\title{
REVIEW
}

\section{Molecular therapies delaying cardiovascular aging: disease- or health-oriented approaches}

\author{
Alessandra Magenta1', Reggio Lorde², Sunayana Begum Syed³, Maurizio C Capogrossi3,4, Annibale Puca5,6 and \\ Paolo Madeddu² \\ ${ }^{1}$ Istituto Dermopatico dell'Immacolata, IDI-IRCCS, Rome, Italy \\ 2Bristol Medical School (Translational Health Sciences), Bristol Heart Institute, University of Bristol, Bristol, UK \\ ${ }^{3}$ Laboratory of Cardiovascular Science, National Institute on Aging, National Institutes of Health, Baltimore, Maryland, USA \\ ${ }^{4}$ Division of Cardiology, Johns Hopkins Bayview Medical Center, Baltimore, Maryland, USA \\ ${ }^{5}$ Ageing Unit, IRCCS MultiMedica, Milan, Italy \\ ${ }^{6}$ Department of Medicine, Surgery and Dentistry, 'Scuola Medica Salernitana' University of Salerno, Baronissi, Italy \\ Correspondence should be addressed to P Madeddu: mdprm@bristol.ac.uk
}

\begin{abstract}
Regenerative medicine is a new therapeutic modality that aims to mend tissue damage by encouraging the reconstitution of physiological integrity. It represents an advancement over conventional therapies that allow reducing the damage but result in disease chronicization. Age-related decline in spontaneous capacity of repair, especially in organs like the heart that have very limited proliferative capacity, contributes in reducing the benefit of conventional therapy. ncRNAs are emerging as key epigenetic regulators of cardiovascular regeneration. Inhibition or replacement of miRNAs may offer reparative solutions to cardiovascular disease. The first part of this review article is devoted to illustrating novel therapies emerging from research on miRNAs. In the second part, we develop new therapeutic concepts emerging from genetics of longevity. Prolonged survival, as in supercentenarians, denotes an exceptional capacity to repair and cope with risk factors and diseases. These characteristics are shared with offspring, suggesting that the regenerative phenotype is heritable. New evidence indicates that genetic traits responsible for prolongation of health span in humans can be passed to and benefit the outcomes of animal models of cardiovascular disease. Genetic studies have also focused on determinants of accelerated senescence and related druggable targets. Evolutionary genetics assessing the genetic basis of adaptation and comparing successful and unsuccessful genetic changes in response to selection within populations represent a powerful basis to develop novel therapies aiming to prolong cardiovascular and whole organism health.
\end{abstract}

\section{Introduction}

The number and proportion of older people is growing in every country in the world. According to data from World Population Prospects (2019 Revision), by 2050, 16\% of the people in the world will be over age 65 , almost doubling the figure in 2019; and the number of persons aged 80 years or over is projected to triple. In Europe and Northern America, the proportion of 65 or over is forecasted to be $25 \%$ by 2050 . This demographic transformation has remarkable social implications, including work, markets, request, and availability of services such as housing, health,

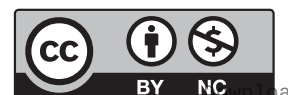

This work is licensed under a Creative Commons Attribution-NonCommercial 4.0 International License. 
and mobility. Prolongation of lifespan correlates with an increased number of individuals with chronic pathologies often requiring hospitalization. Many countries are already facing problems related to the impact of the aging population on the national health system, pension schemes, and social protections. Specific actions on health and nutrition, protecting elderly people, housing and environment, family, and social/medical welfare are in the agenda of policy makers and governmental agencies.

All around the world, scientists are trying to beat age-related diseases, such as heart attacks, cancer, and dementia; stop people getting ill is an obvious goal to aid the individual wellbeing and reduce pressure on society. At the whole organism level, aging has been defined as the time-related deterioration of the physiological functions necessary for survival and fertility. This definition applies to all the individuals of a species and overlaps with disease-related aging. Aging of the vasculature plays a key role in morbidity and mortality of older people. It is often assimilated with endothelial dysfunction, that is, the failure of vascular endothelial cells to respond to vasoactive stimuli and mount reparative transformation upon tissue damage. Zooming into the molecular level, aging of the vasculature consists in small, incremental amounts of damage that spreads to all vascular cells, including vascular smooth muscle cells and pericytes, and, owing to the system dependency on vascular homeostasis, to tissues and organs; eventually, the whole organism will suffer from this accumulation of damage.

In this article, we focus on molecular therapies that can aid an organism to correct deviations from or maintain physiological homeostasis. Two specific fields are considered. A review of recent research on ncRNAs and new genetic approaches inspired by extreme longevity aims to prolong health-span.

\section{Mechanisms of vascular aging}

The development of novel treatments targeting vascular aging and prevention of age-related vascular pathologies requires a better knowledge of the cellular and functional changes that occur in the vasculature during aging. These include oxidative stress, mitochondrial dysfunction, susceptibility to molecular stressors, chronic low-grade inflammation, genomic instability, cellular senescence, epigenetic alterations, loss of proteostasis, deregulated nutrient sensing, and stem cell dysfunction. Senescent cells secrete autocrine or paracrine factors, including cytokines, growth factors, proteases, and soluble receptors called senescence-associated secretory phenotype (SASP) (1). One dominant SASP molecule is the monocyte chemoattractant potein-1 (MCP-1/CCL2) which acts through binding to cognate receptor CCR2. Hence, MCP-1 could be exploited as a marker of cell senescence both in vitro and in vivo. Review articles and commentaries have been published on this topic in recent years $(2,3,4,5,6)$.

The capacity to repair and regenerate empowers living organisms with resilience to natural fluctuations and events that cause disturbance or damage. Aging and regeneration are two sides of the same coin and this has been confirmed through the examination of species with extreme regenerative capabilities, such as planarians and salamanders, which show no signs of aging or quantifiable age-associated functional decline (7). In contrast, in complex organisms like humans, aging is characterized by a decay in the regenerative capacity and reparative activities (8). Tissue-specific stem cells and progenitor cells incur in age-related defects, such as the loss of self-renewal capacities and proliferative activity and the deterioration in functionality and potency (9). Likewise, differentiated cells become progressively uncapable of regulating protein synthesis and metabolism, especially under stress conditions, eventually undergoing irreversible proteotoxic damage (10). Exhaustion of compensatory mechanisms increases the susceptibility to risk factors and diseases and results in excess morbidity and mortality.

\section{miRNAs involved in aging and regeneration}

The first part of this review article is dedicated to the emerging role of miRNA in aging and regeneration. ncRNAs and among these several miRNAs genes can be epigenetically regulated by DNA methylation and/or histone modifications. In addition, a subgroup of miRNAs, named epi-miRNAs, directly target enzymatic effectors involved in epigenetic modulation (11). Therefore, a regulatory loop between epigenetic modulation and miRNAs does exist, which could significantly affect transcription and enhance or slow-down aging and age-related diseases (11). The following miRNAs are either epigenetically regulated or represent epi-miRNAs involved in aging and in cardiovascular regeneration and are summarized in Fig. 1.

\section{The miRNA-200 family}

The miRNA-200 family consists of five members (i.e. miRNA-200a, miRNA-200b, miRNA-200c, miRNA-141,

This work is licensed under a Creative Commons Attribution-NonCommercial 4.0 International License. 


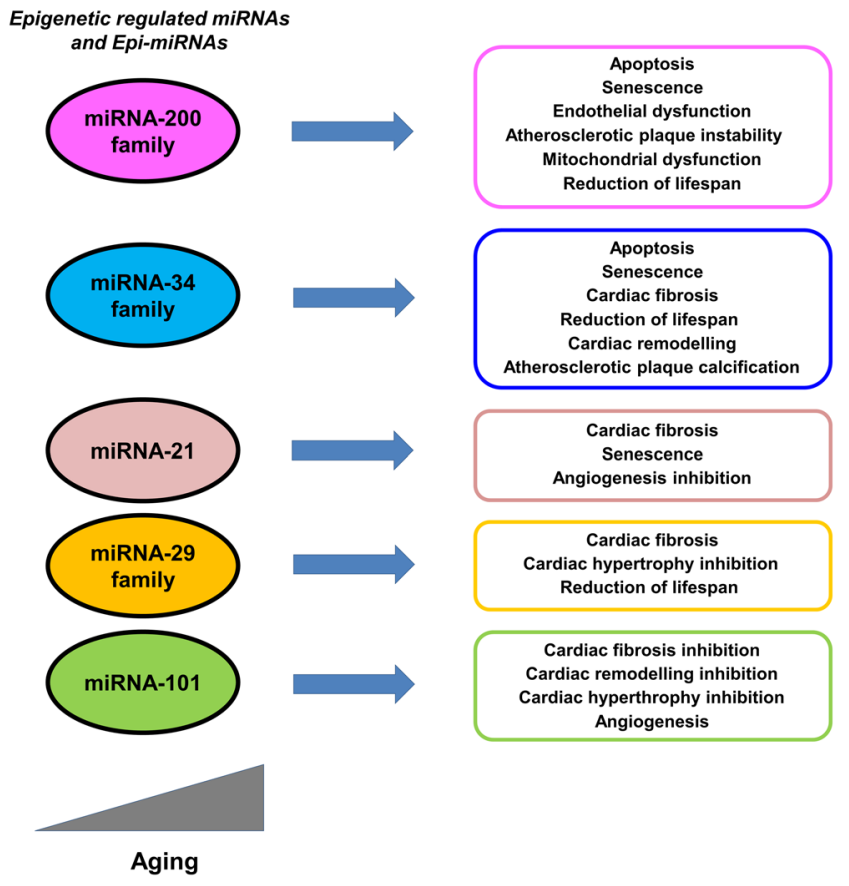

Figure 1

Biological effects of Epi-miRNAs.

and miRNA-429). MiRNA-200 plays a major role in the epigenetic control of tumorigenesis and Epithelial to Mesenchymal transition (EMT) (12). A negative feedback loop between miRNA-200c and DNA methyltransferase 3a (DNMT3a) was shown in gastric cancer cells (13). miRNA-200b has been shown to target Suz12, a subunit of polycomb repressive complex 2 (PCR2) decreasing H3 lysine 27 trimethylation at the promoters of target of E-cadherin, thereby causing transcriptional increase (14). The interaction between miRNA-200 and Suz12 is highly conserved, and it seems to represent a regulatory mechanism to control the growth and function of stem cells.

miRNA-200 upregulation has been linked to aging. In particular, miRNA-200c and miR-141 expressions are increased in skeletal muscles and arteries of aging rhesus monkeys and mice $(15,16)$. miRNA-141 and miRNA-200c increase with aging in human liver (17). In addition, miRNA-200a was found upregulated in primary human keratinocytes from aging individuals (18). miRNA-200 upregulation with aging contributes to the impairment of mechanisms implicated in the repair of oxidative DNA damage in keratinocytes and endothelial cells $(18,19,20)$. The most expressed and induced member, miRNA-200c, is responsible for apoptosis and senescence via downregulation of the transcription factor ZEB1 and a p53 and pRb-dependent mechanism (20).
Moreover, miRNA-200c upregulation induces endothelial dysfunction, since it disrupts the autoregulatory loop among three important proteins for endothelial function: Sirtuin 1 (SIRT1), forkhead box O1 (FOXO1), and the endothelial nitric oxide synthase (eNOS), directly targeting all of them (16). SIRT1 is a major regulator of longevity and metabolic disorders (21). Its downregulation by miRNA-200c results in increased levels of acetylation of both p53 and FOXO1. Acetylated p53 is more active and further induces miRNA-200c. FOXO1 acetylation inhibits its transcriptional activity, with the consequent decrease of catalase and Manganese Superoxide dismutase (MnSOD or SOD2), two ROS-scavengers, finally leading to oxidative stress upregulation (16). In addition, SIRT1 deacetylates eNOS increasing NO bioavailability, while NO stabilizes the mRNA and protein of SIRT1 (22). Since miRNA-200c targets both eNOS and FOXO1, their decrease further contributes to the disruption of the autoregulatory loop inducing endothelial dysfunction (16).

miRNA-200c also plays a major role in cardiovascular diseases (19). miRNA-200c is upregulated in plaques and plasma of atherosclerotic patients, being further enhanced in unstable vs stable carotid plaques (23) and in plasma of children with familiar hypercholesterolemia (24). miRNA-200c was found upregulated in cardiomyopathies induced by doxorubicin (DOX) in mice as well as in human cardiac mesenchymal progenitor cells exposed to DOX (25). Interestingly, stromal cell-derived factor-1 (SDF-1) administration was able to partially revert DOX-induced miRNA-200c and p53 protein upregulation in mouse hearts, and to revert both the adverse remodelling and the impaired ventricular function (25). In addition, miRNA-200c is induced following acute hindlimb ischemia in mice $(16,20)$. Inhibition with antimiRNA-200c increased postischemia reperfusion and reparative angiogenesis (16). Likewise, miRNA-200c inhibition restored endothelial function in diabetes (26) and attenuated cardiomyocyte hypertrophy in high glucose-treated cardiomyocytes (27).

miRNA-141 is involved in mitochondrial dysfunction and in cardiac abnormalities associated with type 1 diabetes (28). It targets the solute carrier family 25 member 3 (SLC25A3), an inner mitochondrial membrane phosphate transporter, which is essential for ATP production since it provides inorganic phosphate to the mitochondrial matrix. SLC25A3 expression is decreased in type 1 diabetes, which has a deleterious effect on ATP production and cell viability (28). Interestingly, miRNA-141 also targets ZMPSTE24, which is involved in the post-translational maturation of lamin A (29). 
ZMPSTE24 is responsible for the prelamin A accumulation in cellular senescence of human mesenchymal stem cells isolated from umbilical cord blood. Moreover, miRNA-141 is upregulated during senescence as a result of epigenetic regulation of its promoter region (29).

Altogether, these data indicate that miRNA-200 is deeply involved in the epigenetic control of aging and regeneration in different tissues and cells. Its manipulation can have beneficial effects on vascular and cardiac function.

\section{The miRNA-34 family}

The miRNA-34 family consists of three highly homologous miRNAs, miRNA-34a, b, and c. It is often epigenetically regulated in different diseases and tumors (30). A miRNA-34a activation has been associated with ethanollinked hypomethylation of the miRNA-34a promoter (31). The miRNA-34a promoter is hypomethylated in preeclamptic placentas (32), and, in cholangiocarcinoma, miRNA-34a expression is silenced epigenetically by EZH2 and DNA methylation (33). In addition, miRNA-34a regulates epigenetic enzymes, such as deacetylases SIRT1 and HDAC1 $(34,35)$.

This miRNA family exhibits an age-dependent increase in different murine tissues, including liver, heart, and brain (36), in rat endothelial progenitor cells (37), and in human vasculature. miRNA-34a is thought to play an important pathogenic role in vascular smooth muscle cells senescence, calcification, and plaque formation through downregulation of SIRT1 and AXL Receptor Tyrosine Kinase $(38,39)$. Accordingly, murine vascular smooth muscle cells lacking miRNA-34a are resistant to develop senescence and calcification (39). Experimental studies using anti-miRNA-34a in high fat diet (HFD)-induced ApoE-/- mice showed reductions in atherosclerotic lesions and vascular cells apoptosis. Likewise, anti-miRNA-34a promoted cell viability and restrained apoptosis in ox-LDL-treated human aortic endothelial cells (40) and induced proliferation in human cardiac progenitor cells (41).

miRNA-34a has been associated to heart failure, where upregulation in cardiomyocytes targets pro-proliferative and pro-survival proteins CyclinD1 and Bcl2 (42). Several days post-MI, older mice exhibited a significant increase of miRNA-34a expression compared to young mice, resulting in a decline of cardiac performances and cardiac remodeling. Inhibition of either miRNA-34a or of the entire miRNA-34 family improves cardiac function in terms of fibrosis, cardiac remodeling, and cardiomyocyte death in models of myocardial infarct (42). Higher miRNA-34a levels have been found in diabetes; in particular, miRNA-34a is elevated in plasma of diabetic patients and is upregulated in cardiac progenitor cells and cardiomyocytes exposed to high glucose, suggesting an inductive role of senescence in the diabetic heart (43).

miRNA-34 has been associated with reduction of lifespan. Interestingly, miRNA-34 is upregulated during C. elegans aging where it appears to antagonize longevity by repressing the autophagy gene atg9 (44). In Drosophila, miRNA-34 has been shown to be essential for normal aging. Loss-of-function mutants of miRNA-34 display shorter lifespan through EIP74, an ecdysone-induced transcription factor (45).

In summary the miRNA-34 family plays a pivotal role in the epigenetic control of lifespan and is pathogenically involved in atherosclerosis, vascular calcification, cardiac fibrosis, and adverse remodeling in heart failure. Its inhibition can improve cardiovascular repair.

\section{miRNA-21}

miR-21 is epigenetically regulated in ovarian cancer and colorectal cancer $(46,47)$. miRNA-21 expression increases with aging in murine hearts and plays a major role in cardiac fibrosis in mice and in patients with aortic stenosis $(48,49)$. In a mouse model of acute cardiac allograft transplantation, it activates mitogen-activated protein kinase (MAPK) signaling in fibroblasts inducing cardiac fibrosis (50). Suppression of miRNA-21 prevents cardiomyocyte senescence induced by d-galactose and DOX (51) and promotes angiogenesis by restoring Ras homolog family member B (52).

\section{The miRNA-29 family}

The miRNA-29 family consists of three members, miRNA29a, miRNA-29b, and miRNA-29c. It acts as a regulator of cell survival by inducing global DNA hypomethylation. It has been shown to directly target DNA methyltransferases $D N M T-3 A$ and DNMT-3B in lung cancer (53) and indirectly DNA methyl transferase DNMT1 through the regulation of the trans-activator Sp1 in leukemia (54).

miRNA-29 is upregulated in aging hearts and its dysregulation after myocardial infarction induces the activation of TGFB causing cardiac fibrosis (55). MiRNA-29b administration inhibits $\mathrm{TGFb} / \mathrm{Smad} 3$ signaling in hypertensive rats preventing cardiac fibrosis (56). An inverse correlation of circulating miRNA-29a with cardiac

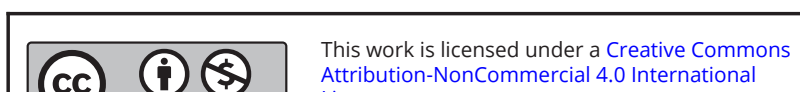
Attribution-NonCommercial 4.0 International License. 
fibrosis has been found in the plasma of patients with cardiac hypertrophy (57).

miRNA-29 modulates vascular function, as demonstrated by studies in diabetic models, in which intraluminal delivery of miRNA-29a or miRNA-29b restored normal endothelium-dependent vasodilation increasing $\mathrm{NO}$ availability. Thus, miRNA mimics may have therapeutic potential for cardiometabolic disorders (58). Interestingly, another miRNA-29 target is the prelamin A interacting protein (59). miRNA-29 is induced in a model of HGP syndrome, the Zmpste24-deficient mice, reflecting a p53-dependent compensatory response to DNA damage (59). miRNA-29 targets Ppm1d phosphatase, which in turn enhances p53 activity, inducing further miRNA-29 upregulation and eventually decreasing cell survival and proliferation (59).

\section{miRNA-101}

miRNA-101 is an epi-miRNA that targets both EZH2 (60) and EED (61), two pivotal components of histone methyltransferase PCR2 complex, involved in cell proliferation and differentiation. Moreover, miRNA-101 increases with aging in brain (62). Following coronary artery ligation, miRNA-101 levels are downregulated in both rat cardiac fibroblasts and myocytes. MiRNA101 overexpression inhibits fibrosis and adverse cardiac remodelling through inhibition of c-FOS, a transcriptional modulator of TGFb (63). In a rat model of hypertrophy, miRNA-101 overexpression inhibited cardiomyocytes hypertrophy through the downregulation of its target small GTPase Rab1a (64). Finally, miRNA-101 is downregulated upon VEGF treatment, resulting in increased expression of the histone methyltransferase EZH2 in endothelial cells and promotion of angiogenesis (65).

In summary, miRNA-101 modulates epigenetic and cardiovascular homeostasis, although its modulation with aging in cardiovascular tissues remains unexplored.

\section{Noncoding RNAs that sponge miRNAs involved in aging and regeneration}

In the last decades, other ncRNAs, such as long ncRNAs (lncRNAs) and circular RNAs (circRNAs), have been discovered and attracting attention in research. LncRNAs are ncRNAs that are $200 \mathrm{nt}$ longer, usually polyadenylated, capped, and spliced (66). LncRNAs are transcribed from different genomic regions, such as intergenic regions, promoter upstream regions, enhancers, and the opposite strand of protein-coding genes. Some lncRNAs are generated by unique biogenesis, such as RNase P cleavage and capping by snoRNA-protein (snoRNP) complexes at their ends (67).

CircRNAs are ncRNAs characterized by a covalently closed continuous loop without polarity or a polyadenylated tail (68). CircRNAs usually originate from protein-coding genes and complete exons (69) and are mainly produced during splicing. CircRNAs are resistant to exonucleases due to lack of free ends. They also have potential to roll circle amplification, constrain RNA folding, and rearrange genomic sequences (70). The most important function of circRNAs is miRNA sponge, where they regulate miRNAs. However, it is shown previously that some circRNAs are translated into polypeptides $(69,71)$.

Here we will discuss relevant lncRNAs and circRNAs known to sponge relevant miRNAs described previously that are known to have a role in cardiovascular aging and/ or regeneration (Table 1).

Long noncoding RNAs (IncRNAs) and circular RNAs (circRNAs) that sponge miRNA-200 family

lncRNA MALAT1 (metastasis associated lung adenocarcinoma transcript 1 ) has been associated to miR-200 family in different studies related with cancers $(72$, $73,74)$. Interestingly, its modulation has also been linked to CVD. Higher expression of MALAT1 was observed in both humans and rodents with MI, myocardial ischemiareperfusion injury, and cardiomyocytes of arrhythmic rats $(75,76)$.

The role of MALAT1 in miR-200c/HMGB1 pathway was studied in arrhythmic rat model and shows that highmobility group box 1 (HMGB1) acts as a downstream target of miR-200 family. miR-200 family inhibits HMGB1 expression at both mRNA and protein levels. MALAT1 sponges miR-200c causing HMGB1 upregulation and thereby downregulating cardiac transient outward potassium current (Ito) associated arrhythmia (76). Further, in mice undergoing coronary artery ligation to produce acute MI, exogenous HMGB1 has been shown to promote cardiac repair, to improve cardiac function (77), and to inhibit adverse remodeling via an increase in miR-206 that directly targets Tissue Inhibitor of Metalloproteinase-3 (TIMP3) (78). Knockdown of MALAT1 or overexpression of miR-200c reduces HMGB1 expression level, indicating that MALAT1 sponges miR200c to promote HMGB1 expression. Moreover, MALAT1 modulates outward potassium and repolarization currents

This work is licensed under a Creative Commons Attribution-NonCommercial 4.0 International License. 


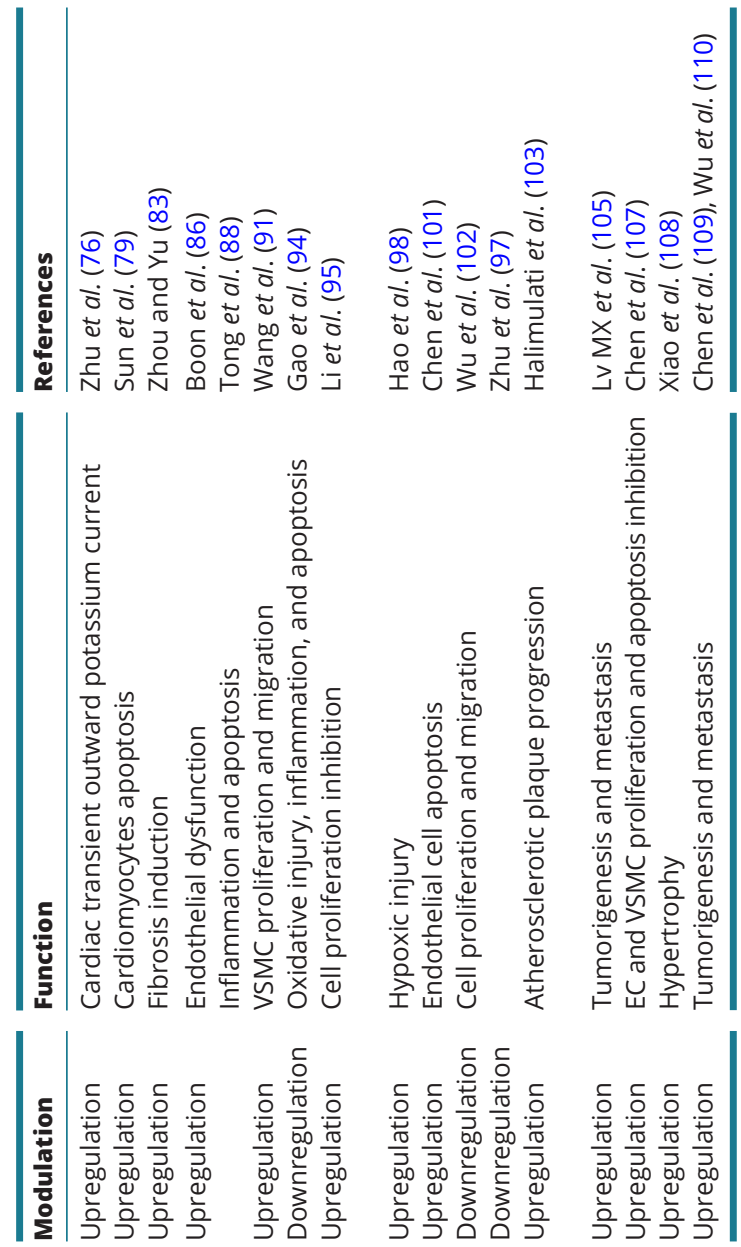

that are involved in myocardial function. In hypoxiainduced cardiomyocytes, MALAT1 sponges miR-200a and upregulates programmed cell death 4 (PDCD4) expression, indicating that MALAT1-miR-200a-PDCD4 axis regulates cell cycle progression, proliferation, and apoptosis in myocardial cells (79).

\section{LncRNAs and circRNAs that sponge miRNA-141}

Several studies have shown the interaction of miR-141 with IncRNAs in different diseases including cancers $(80,81,82)$. However, only few studies are available on lncRNAs and circRNAs that sponge miR-141 in CVD.

Among these circRNA_010567 is a fibrosis-promoting RNA upregulated in myocardium of diabetic mice and in cardiac fibroblasts (CFs) treated with Ang II (83). In db/db mice model, it was found that circRNA_010567 directly binds to miR-141. Indeed, silencing of circRNA_010567 results in upregulation of miR-141 and downregulation of its target TGF-b1, thereby causing the suppression of fibrosis associated protein resection in cardiac fibroblasts. This indicates that circRNA_010567/miR-141/TGF- $\beta 1$ axis plays a major role in myocardial fibrosis (83).

\section{LncRNAs and circRNAs that sponge miRNA-34 family}

Maternally expressed gene 3 (MEG3) is a highly expressed IncRNA associated with myocardial infarction, transverse aortic constriction (TAC), and cardiac hypertrophy $(84,85)$. It contributes to endothelial dysfunction by mediating epigenetic regulations in aging (86). MEG3 inhibition in cardiac fibroblasts prevents cardiac fibrosis and improves diastolic performance (87). miR-34a is a direct target of MEG3 (88). In vivo studies on hepatocyte ischemia-reperfusion (HIR) injury revealed that MEG3 functions as a competing endogenous RNA for miR-34a. It downregulates miR-34a expression and protects hepatocytes from HIR injury mediated through 34a/Nrf2 signaling pathway (89). Further, in diabetic retinopathy, MEG3 targets miR-34a/SIRT1 axis and alleviates high glucose inducing apoptosis, as well as inflammation by inhibiting the NF-kB signaling pathway (88).

Another IncRNA that shows a role in coronary artery disease (CAD) is C2dat1. LncRNA C2dat1 is a CaMK2Dassociated transcript 1 . LncRNA shows higher expression in CAD (90). C2dat1 binds to miR-34a and modulates its expression in CAD. Overexpression of C2dat1 suppresses miR-34a expression and upregulates its target protein SIRT1, increasing VSMC growth and migration in CAD (91). 
LncRNA HOX transcript antisense RNA (HOTAIR) is a highly conserved and abundant lncRNA associated with various essential biological processes involved in different diseases. Increased expression of HOTAIR was observed in both plasma and cardiac tissues of patients with cardiac hypertrophy $(92,93)$. In contrast, diabetic mice showed a significant decrease in the expression of HOTAIR in heart tissues. HOTAIR knockdown in H9C2 rat cardiomyoblast cell line resulted in an elevated oxidative injury, inflammation, and apoptosis, whereas HOTAIR overexpression attenuated myocyte death and improved cardiac function. HOTAIR, in fact, functions as a competing endogenous RNA (ceRNA) of miR-34a. It has been demonstrated that HOTAIR sponges miR-34a, causing upregulation of SIRT1 expression and protecting mice from diabetic cardiomyopathy (94).

LincRNA 1700020I14Rik is another IncRNA that regulates miR-34a-5p/Sirt1/HIF-1 $\alpha$ signaling pathway by inhibiting cell proliferation, as well as fibrosis in diabetic nephropathy. Under elevated glucose condition, overexpression of lncRNA 1700020I14Rik prevents the expression of renal fibrosis markers and decreases cell proliferation, whereas its downregulation produces the opposite effect (95).

Although no studies have been published on LincRNA 1700020I14Rik and the heart and blood vessels, these observations raise the possibility of a link between LincRNA 1700020I14Rik and cardiovascular disease in diabetic patients with renal failure.

\section{LncRNAs and circRNAs that sponge miRNA-21}

miR-21 is a highly expressed microRNA in the cardiovascular system; it attenuates inflammation, maladaptive remodeling, and cardiac dysfunction in post myocardial infarction (96). Recent studies have reported that miR-21 expression can be modulated by other ncRNA associated with various molecular pathways (97).

TALNEC2 is a E2F1-regulated putative IncRNA, also known as Tumor Associated Long ncRNA Expressed on Chromosome 2. High expression of TALNEC2 was observed in myocardial ischemic patients. Studies on H9c2 cells showed that TALNEC2 modulates miR-21 expression under hypoxic condition. Overexpression of TALNEC2 aggravates hypoxic injury by downregulating miR-21 via the regulation of miR-21/PDCD4-mediated activation of the $\mathrm{Wnt} / \beta$-catenin signaling pathway in myocardial ischemic injury (98).

Long ncRNA taurine upregulated gene 1, also known as IncRNA TUG1, is known to promote VSMC proliferation and to induce atherosclerosis progression. High expression of TUG1 was observed in atherosclerosis and hypoxia (99, 100). LncRNA TUG1 overexpression induces endothelial cell apoptosis, and its knockdown decreases apoptotic ratio and promotes cell survival (101). Further, LncRNA TUG1 competes with phosphatase and tensin homolg (PTEN) for miR- 21 binding. Downregulation of TUG1 markedly inhibit the expression of miRNA-21, indicating that IncRNA TUG1 promotes VSMC proliferation and atherosclerosis by regulating miRNA-21/PTEN axis $(99,100)$.

LncRNA MEG3, as described previously, is a vastly expressed lncRNA associated with $\operatorname{CVD}(84,85)$. In contrast, some studies showed the reduced expression of lncRNA MEG3 in CVD and Hypoxia-induced pulmonary hypertension $(97,102)$. It has been shown that miR-21 is a direct target of MEG3. In CAD, MEG3 is downregulated and negatively correlates with miR-21 levels. MEG3 overexpression suppresses EC proliferation and migration and reduces the expression of proteoglycan, type I, and $\mathrm{V}$ collagen through the decrease of miR-21 (102). Its inhibition promotes cell proliferation and migration in normal and hypoxic conditions through the miR-21/PTEN axis. Under hypoxic condition, MEG3 binds miR-21 and modulates PTEN expression resulting in cell proliferation and migration in pulmonary arterial smooth muscle cells (PASMCs) (97).

TCONS_00024652 is an endothelium-associated lncRNA involved in plaque angiogenesis and atherosclerosis progression. High expression of TCONS_00024652 was observed in TNF- $\alpha$-stimulated HUVECs. The interaction of miR-21 with lncRNA TCONS_00024652 was determined using bioinformatics and molecular techniques. TNF$\alpha$ treatment increases TCONS_00024652 expression in a dose dependent manner, and its knockdown inhibits proliferation and angiogenesis in endothelial cells. Binding of miR-21 to TCONS_00024652 reduces its expression and may be a potential method of improving endothelial dysfunction and plaque stabilization (103).

\section{LncRNAs and circRNAs that sponge miRNA-29 family}

Long ncRNA H19 is a paternally imprinted gene located on chromosome 11p15.5. Several studies reported the significant increase of lncRNA H19 in various human cancers associated with tumorigenesis and metastasis (104). The IncRNA H19 directly binds to miR-29b-3p and lowers the expression of DNA Methyltransferase 3 Beta (DNMT3B) epigenetic enzyme (105). Interestingly, LncRNA H19 has been reported to be upregulated in

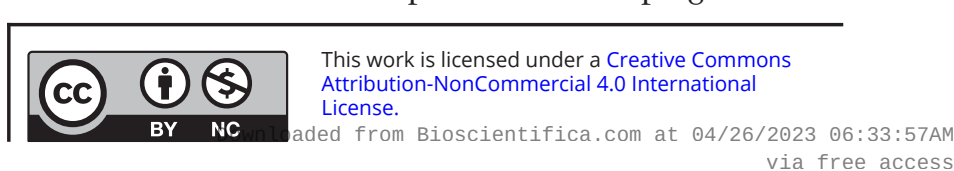


atherosclerotic patients and to cause the increase of acid phosphatase 5 gene (106). The latter encodes a metalloenzyme named tartrate-resistant acid phosphatase (TRAP) that is significantly associated with cancer progression, and it is known to induce endothelial and VSMC proliferation and suppress apoptosis (107).

Although a direct link of RNA H19 and miR-29 family has not been described in CVD, it is possible that their association may modulate atherosclerosis progression.

\section{LncRNAs and circRNAs that sponge miRNA-101}

X-inactive specific transcript (XIST) is a lncRNA that regulates cardiac hypertrophy. Significantly upregulated expression of lncRNA XIST was observed in hypertrophic mouse heart, postmyocardial infarction cells, as well as in $\mathrm{H9c} 2$ cells treated with phenylephrine (PE) (108). Recently, it was shown that XIST competitively binds to miR-101 and promotes cardiac hypertrophy by enhancing the expression of Toll-like receptor 2 (TLR2) (108).

Further, in gastric and esophageal squamous cell carcinoma, lncRNA XIST modulates epigenetic mechanisms through the regulation of miR-101/EZH2 pathway causing cancer $(109,110)$.

\section{Genetics of extreme longevity: can this inform new therapy sustaining health-span?}

Although prolonged lifespan does not always correspond to health span, extreme longevity is often accompanied by reduced or delayed morbidity $(111,112)$. This led to the hypothesis that the aging-related decay is neither necessary nor irreversible (111). Genetic association investigation identified several candidate gene variants that segregate with exceptional longevity, which have been revised using a meta-analysis approach (113). Strength and limitations of the most powerful and used tools, such as genome-wide association study (GWAS) and whole-genome sequencing, have been recently reviewed by Giuliani et al. (114). The major results of this approach suggest that the genetics of longevity is highly population specific; small-effect alleles, pleiotropy, and the complex allele timing likely play a major role; and a close relationship between genetics of longevity and genetics of age-related diseases (including cardiovascular diseases) do exist. One important aspect in this as in other fields of research is reproducibility of the data. Some loci, such the one at chromosome 5q33.3, failed to show association in a replication analysis (115), while mutations located near APOE/TOMM40 have been replicated $(116,117,118,119)$ and confirmed in GWAS at genome-wide significance $(115,120,121,122)$. The e2e2 or e2e 3 genotype is associated with significantly increased odds to reach extreme longevity, whereas the APOEe4 allele is thought to contribute to morbidity and earlier and higher mortality (123).

\section{Translation to therapy of promising genes emerging from GWAS}

APOE4-targeted therapeutic approaches that have been developed in animal models of Alzheimer disease and myocardial ischemia and are close to be translated to humans (124). ApoE is a ligand for low-density lipoprotein LDL receptors, plays a role in lipid metabolism, and is pathogenically implicated in cardiovascular diseases. For instance, apoE4 can affect cerebrovascular integrity by several mechanisms, one of which consists of the accumulation of $\mathrm{A} \beta$ in the cerebral vasculature. Potential therapies targeting ApoE comprise of silencing the gene by CRISP/Cas9 editing, anti-ApoE4 immunotherapy, structure correction or degradation, or use of molecules interacting with the protein or related signaling.

A GWAS performed on an Italian set of long living individuals (LLIs) and controls identified the BPI FoldContaining Family B member 4 (BPIFB4) gene to be associated with lifespan, a result validated on two independent populations from Germany and USA (125). The minor allele rs2070325 is part of a SNP haplotype that codifies for a wild type variant (WT), a longevity-associated variant (LAV), and a rare variant (RV) of BPIFB4. The levels of immunoreactive BPIFB4 protein are reportedly higher in plasma and hematopoietic cells of healthy LLIs compared with diseased LLIs or young controls $(126,127)$. Overexpression of LAV-BPIFB4 induced the activation of stress response-related heat-shock proteins, improved proteostasis, and increased nitric oxide availability in human cells (125). Studies in experimental models of cardiovascular disease showed that viralvector mediated transfer of the human LAV-BPIFB4 gene attenuates hypertension, atherosclerosis, and ischemic disease $(125,128,129,130,131)$. Preclinical results on BPIFB4 gene therapy provides compelling experimental evidence for the potential of transferring the healthy features of centenarians to individuals at risk. A major concept emerging from studies using LAV-BPIFB4 is that gene transfer modified the molecular landscape without reversing it to that of normal controls. This is in keeping with the fact that centenarians experience age-related

This work is licensed under a Creative Commons Attribution-NonCommercial 4.0 International License. 
diseases but cope better with them, possibly through amplification of unconventional molecular mechanisms able to override the pathological process. Clinical studies confirming safety and efficacy will determine if this novel modality may have a disruptive impact on current therapeutic modalities

\section{Lessons from genetics of restricted lifespan}

The Hutchinson-Gilford Progeria Syndrome (HGPS), a fast aging disorder, is characterized by an increased risk of atherosclerosis-induced complications, such as heart attack and stroke (132). The phenotypic effects are brought about by the mutation-induced expression of the progerin protein, a truncated splice variant of the nuclear architectural lamin A (132). This protein plays a role in nuclear structural stability and other nuclear functions such as DNA replication, DNA repair, and chromatin and nuclear pore complex organization. Maturation and stabilization of lamin A requires the cleavage of the farnesylated C-terminus by a zinc metalloprotease. Due to aberrant splicing, the lamin A variant progerin is truncated and remains stuck in its immature form. This leads to delocalization of nuclear envelope proteins, disorganized heterochromatin and nuclear pore complexes, disrupted nuclear morphology, and increased DNA damage and repair. Cells affected by progerin expression have increased nuclear rigidity and are more sensitive to mechanical strain. Phenotypic symptoms of HGPS are especially seen in tissues with high levels of mechanical stress such as bone, skeletal muscle, the heart, and blood vessels $(132,133)$.

Interestingly, progerin is not only present in the cases of HGPS patients, being also expressed in healthy aging individuals though to a lesser degree. This stands to reason that some of the modalities used to treat HGPS might be replicated or adapted to combat age-associated cardiovascular regenerative decline $(134,135)$. Progerin activates and dysregulates various downstream of Notch, including HES1, HES5, and HEY (135). It was therefore suggested that using inhibitors of the Notch signaling pathway could be a viable option to combat cardiovascular aging $(135,136)$. Recovery from an ischemic insult requires the activation of inflammatory cells and vascular cells and timely resolution of the initial sterile inflammation. In a murine model, we showed that targeting the Dll4/Notch signaling could have a relevant impact on coordinating reparative angiogenesis and inflammation under ischemic conditions (137).
More than $70 \%$ of UK adults aged 25 and over have low vitamin D levels. This can have an impact on precocious senescence. In fact, it was shown that HGPS cells have reduced expression of vitamin D receptor (VDR), and that reconstituting VDR signaling via $1 \alpha, 25$-dihydroxyvitamin D3 treatment alleviates HGPS phenotypes, including nuclear morphological abnormalities, DNA repair defects, and premature senescence (138). Interestingly, vitamin D supplementation delayed epigenetic aging in overweight and obese non-HGPS individuals with suboptimal vitamin D status (139). Therefore, supplementation of this nutrient can be a viable method to improve health span in the general population.

Taking a closer look at the mechanisms by which progerin may be linked to physiological aging has revealed another mode of treatment (140). Progerin mRNA levels and levels of progerin do not increase with age; therefore, the hallmarks of aging are not related to an accumulation of progerin over time (140). Rather, the presence and expression of progerin mRNA in the nucleus leads to the delocalization and accumulation of wild type lamin A at the nuclear rim (140). In vivo, targeting the cryptic splice site in the gene with a morpholino oligonucleotide (Exo11) via electroporation of affected cells reversed the aberrant cellular phenotypes $(140,141)$.

\section{Conclusions}

Evidence form the literature highlights the complex molecular machinery involved in the dysregulation of cardiovascular function with aging. Investigation of mechanisms that allow the maintenance of health during aging or inhibit genetic programs of premature senescence could provide novel therapeutic modalities superior to current treatments. Much more research, refinement, and preclinical testing are, however, required before these treatments enter the clinical stage.

\section{Declaration of interest}

M C C and P M are Editors of Vascular Biology. M C C and P M were not involved in the review or editorial process of this paper, on which they are listed as authors. The other authors have nothing to disclose.

\section{Funding}

This study was partly supported by a British Heart Foundation project grant (R100465) to P M; by the Italian Ministry of Health RF-02362708 grant to A M and M C C; by AFM Telethon 22522 grant to A M; by Idi-Farmaceutici s.r.l. grant IDI FAR18MG to A M; and by the Intramural research Program of the NIH, National institute on Aging to M C C. 


\section{References}

1 Acosta JC, Banito A, Wuestefeld T, Georgilis A, Janich P, Morton JP, Athineos D, Kang TW, Lasitschka F, Andrulis M, et al. A complex secretory program orchestrated by the inflammasome controls paracrine senescence. Nature Cell Biology 201315 978-990. (https:// doi.org/10.1038/ncb2784)

2 Ungvari Z, Tarantini S, Donato AJ, Galvan V \& Csiszar A Mechanisms of vascular aging. Circulation Research 2018123 849-867. (https:// doi.org/10.1161/CIRCRESAHA.118.311378)

3 Fontana L Interventions to promote cardiometabolic health and slow cardiovascular ageing. Nature Reviews: Cardiology 201815 566-577. (https://doi.org/10.1038/s41569-018-0026-8)

4 Ferrucci L \& Fabbri E Inflammageing: chronic inflammation in ageing, cardiovascular disease, and frailty. Nature Reviews: Cardiology 201815 505-522. (https://doi.org/10.1038/s41569-018-0064-2)

5 Gude NA, Broughton KM, Firouzi F \& Sussman MA Cardiac ageing: extrinsic and intrinsic factors in cellular renewal and senescence. Nature Reviews: Cardiology 201815 523-542. (https://doi. org/10.1038/s41569-018-0061-5)

6 Lakatta EG The reality of getting old. Nature Reviews: Cardiology 2018 15 499-500. (https://doi.org/10.1038/s41569-018-0068-y)

7 Yun MH Changes in regenerative capacity through lifespan. International Journal of Molecular Sciences 201516 25392-25432. (https://doi.org/10.3390/ijms161025392)

8 Lopez-Otin C, Blasco MA, Partridge L, Serrano M \& Kroemer G The hallmarks of aging. Cell 2013153 1194-1217. (https://doi. org/10.1016/j.cell.2013.05.039)

9 Cesselli D, Aleksova A, Sponga S, Cervellin C, Di Loreto C, Tell G \& Beltrami AP Cardiac cell senescence and redox signaling. Frontiers in Cardiovascular Medicine 20174 38. (https://doi.org/10.3389/ fcvm.2017.00038)

10 Hill SM, Hanzen S \& Nystrom T Restricted access: spatial sequestration of damaged proteins during stress and aging. EMBO Reports 201718 377-391. (https://doi.org/10.15252/ embr.201643458)

11 Iorio MV, Piovan C \& Croce CM Interplay between microRNAs and the epigenetic machinery: an intricate network. Biochimica and Biophysica Acta 20101799 694-701. (https://doi.org/10.1016/j. bbagrm.2010.05.005)

12 Brabletz S \& Brabletz T The ZEB/miR-200 feedback loop--a motor of cellular plasticity in development and cancer? EMBO Reports 201011 670-677. (https://doi.org/10.1038/embor.2010.117)

13 Li Y, Nie Y, Tu S, Wang H, Zhou Y, Du Y, Cao J \& Ye M Epigenetically deregulated miR-200c is involved in a negative feedback loop with DNMT3a in gastric cancer cells. Oncology Reports 201636 2108-2116. (https://doi.org/10.3892/or.2016.4996)

14 Iliopoulos D, Lindahl-Allen M, Polytarchou C, Hirsch HA, Tsichlis PN $\&$ Struhl K Loss of miR-200 inhibition of Suz12 leads to polycombmediated repression required for the formation and maintenance of cancer stem cells. Molecular Cell 201039 761-772. (https://doi. org/10.1016/j.molcel.2010.08.013)

15 Mercken EM, Majounie E, Ding J, Guo R, Kim J, Bernier M, Mattison J, Cookson MR, Gorospe M, de Cabo R, et al. Age-associated miRNA alterations in skeletal muscle from rhesus monkeys reversed by caloric restriction. Aging 20135 692-703. (https://doi. org/10.18632/aging.100598)

16 Carlomosti F, D'Agostino M, Beji S, Torcinaro A, Rizzi R, Zaccagnini G, Maimone B, Di Stefano V, De Santa F, Cordisco S, et al. Oxidative stress-induced miR-200c disrupts the regulatory loop among SIRT1, FOXO1, and eNOS. Antioxidants and Redox Signaling 201727 328-344. (https://doi.org/10.1089/ars.2016.6643)

17 Capri M, Olivieri F, Lanzarini C, Remondini D, Borelli V, Lazzarini R, Graciotti L, Albertini MC, Bellavista E, Santoro A, et al. Identification of miR-31-5p, miR-141-3p, miR-200c-3p, and GLT1 as human liver aging markers sensitive to donor-recipient age-mismatch in transplants. Aging Cell 201716 262-272. (https://doi.org/10.1111/ acel.12549)

18 Tinaburri L, D’Errico M, Sileno S, Maurelli R, Degan P, Magenta A \& Dellambra E miR-200a modulates the expression of the DNA repair protein OGG1 playing a role in aging of primary human keratinocytes. Oxidative Medicine and Cellular Longevity 20182018 9147326. (https://doi.org/10.1155/2018/9147326)

19 Magenta A, Ciarapica R \& Capogrossi MC The emerging role of miR200 family in cardiovascular diseases. Circulation Research 2017120 1399-1402. (https://doi.org/10.1161/CIRCRESAHA.116.310274)

20 Magenta A, Cencioni C, Fasanaro P, Zaccagnini G, Greco S, SarraFerraris G, Antonini A, Martelli F \& Capogrossi MC miR-200c is upregulated by oxidative stress and induces endothelial cell apoptosis and senescence via ZEB1 inhibition. Cell Death and Differentiation 201118 1628-1639. (https://doi.org/10.1038/cdd.2011.42)

21 Yuan Y, Cruzat VF, Newsholme P, Cheng J, Chen Y \& Lu Y Regulation of SIRT1 in aging: roles in mitochondrial function and biogenesis. Mechanisms of Ageing and Development 2016155 10-21. (https://doi. org/10.1016/j.mad.2016.02.003)

22 Potente M \& Dimmeler S Emerging roles of SIRT1 in vascular endothelial homeostasis. Cell Cycle 20087 2117-2122. (https://doi. org/10.4161/cc.7.14.6267)

23 Magenta A, Sileno S, D'Agostino M, Persiani F, Beji S, Paolini A, Camilli D, Platone A, Capogrossi MC \& Furgiuele S Atherosclerotic plaque instability in carotid arteries: miR-200c as a promising biomarker. Clinical Science 2018132 2423-2436. (https://doi. org/10.1042/CS20180684)

24 D'Agostino M, Martino F, Sileno S, Barilla F, Beji S, Marchetti L, Gangi FM, Persico L, Picozza M, Montali A, et al. Circulating miR-200c is up-regulated in paediatric patients with familial hypercholesterolaemia and correlates with miR-33a/b levels: implication of a ZEB1-dependent mechanism. Clinical Science 2017 131 2397-2408. (https://doi.org/10.1042/CS20171121)

25 Beji S, Milano G, Scopece A, Cicchillitti L, Cencioni C, Picozza M, D'Alessandra Y, Pizzolato S, Bertolotti M, Spaltro G, et al. Doxorubicin upregulates CXCR4 via miR-200c/ZEB1-dependent mechanism in human cardiac mesenchymal progenitor cells. Cell Death and Disease 20178 e3020. (https://doi.org/10.1038/cddis.2017.409)

26 Zhang H, Liu J, Qu D, Wang L, Luo JY, Lau CW, Liu P, Gao Z, Tipoe GL, Lee HK, et al. Inhibition of miR-200c restores endothelial function in diabetic mice through suppression of COX-2. Diabetes 201665 1196-1207. (https://doi.org/10.2337/db15-1067)

27 Singh GB, Raut SK, Khanna S, Kumar A, Sharma S, Prasad R \& Khullar M MicroRNA-200c modulates DUSP-1 expression in diabetesinduced cardiac hypertrophy. Molecular and Cellular Biochemistry 2017424 1-11. (https://doi.org/10.1007/s11010-016-2838-3)

28 Baseler WA, Thapa D, Jagannathan R, Dabkowski ER, Croston TL \& Hollander JM miR-141 as a regulator of the mitochondrial phosphate carrier (Slc25a3) in the type 1 diabetic heart. American Journal of Physiology: Cell Physiology 2012303 C1244-C1251. (https://doi. org/10.1152/ajpcell.00137.2012)

29 Yu KR, Lee S, Jung JW, Hong IS, Kim HS, Seo Y, Shin TH \& Kang KS MicroRNA-141-3p plays a role in human mesenchymal stem cell aging by directly targeting ZMPSTE24. Journal of Cell Science 2013 126 5422-5431. (https://doi.org/10.1242/jcs.133314)

30 Kunej T, Godnic I, Ferdin J, Horvat S, Dovc P \& Calin GA Epigenetic regulation of microRNAs in cancer: an integrated review of literature. Mutation Research 2011717 77-84. (https://doi.org/10.1016/j. mrfmmm.2011.03.008)

31 Meng F, Glaser SS, Francis H, Yang F, Han Y, Stokes A, Staloch D, McCarra J, Liu J, Venter J, et al. Epigenetic regulation of miR-34a expression in alcoholic liver injury. American Journal of Pathology 2012181 804-817. (https://doi.org/10.1016/j. ajpath.2012.06.010)

32 Doridot L, Houry D, Gaillard H, Chelbi ST, Barbaux S \& Vaiman D miR-34a expression, epigenetic regulation, and function in

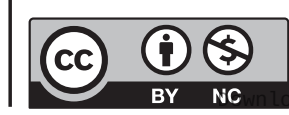

This work is licensed under a Creative Commons Attribution-NonCommercial 4.0 International License. ded from Bioscientifica.com at 04/26/2023 06:33:57AM 
human placental diseases. Epigenetics 20149 142-151. (https://doi org/10.4161/epi.26196)

33 Kwon H, Song K, Han C, Zhang J, Lu L, Chen W \& Wu T Epigenetic silencing of miRNA-34a in human cholangiocarcinoma via EZH2 and DNA methylation: impact on regulation of notch pathway. American Journal of Pathology 2017187 2288-2299. (https://doi.org/10.1016/j. ajpath.2017.06.014)

34 Sun TY, Xie HJ, Li Z, Kong LF, Gou XN, Li DJ, Shi YJ \& Ding YZ miR-34a regulates HDAC1 expression to affect the proliferation and apoptosis of hepatocellular carcinoma. American Journal of Translational Research 20179 103-114.

35 Yamakuchi M, Ferlito M \& Lowenstein CJ miR-34a repression of SIRT1 regulates apoptosis. PNAS 2008105 13421-13426. (https://doi. org/10.1073/pnas.0801613105)

36 Smith-Vikos T \& Slack FJ MicroRNAs and their roles in aging. Journal of Cell Science 2012125 7-17. (https://doi.org/10.1242/jcs.099200)

37 Zhao T, Li J \& Chen AF MicroRNA-34a induces endothelial progenitor cell senescence and impedes its angiogenesis via suppressing silent information regulator 1. American Journal of Physiology: Endocrinology and Metabolism 2010299 E110-E116. (https://doi.org/10.1152/ajpendo.00192.2010)

38 Raitoharju E, Lyytikainen LP, Levula M, Oksala N, Mennander A, Tarkka M, Klopp N, Illig T, Kahonen M, Karhunen PJ, et al. miR21, miR-210, miR-34a, and miR-146a/b are up-regulated in human atherosclerotic plaques in the Tampere Vascular Study. Atherosclerosis 2011219 211-217. (https://doi.org/10.1016/j. atherosclerosis.2011.07.020)

39 Badi I, Mancinelli L, Polizzotto A, Ferri D, Zeni F, Burba I, Milano G, Brambilla F, Saccu C, Bianchi ME, et al. miR-34a promotes vascular smooth muscle cell calcification by downregulating SIRT1 (sirtuin 1) and axl (AXL receptor tyrosine kinase). Arteriosclerosis, Thrombosis, and Vascular Biology 201838 2079-2090. (https://doi.org/10.1161/ ATVBAHA.118.311298)

40 Su G, Sun G, Liu H, Shu L \& Liang Z Downregulation of miR34 a promotes endothelial cell growth and suppresses apoptosis in atherosclerosis by regulating Bcl-2. Heart and Vessels 201833 1185-1194. (https://doi.org/10.1007/s00380-018-1169-6)

41 Iannolo G, Sciuto MR, Raffa GM, Pilato M \& Conaldi PG MiR34 inhibition induces human heart progenitor proliferation. Cell Death and Disease 20189 368. (https://doi.org/10.1038/s41419-018-0400-9)

42 Yang Y, Cheng HW, Qiu Y, Dupee D, Noonan M, Lin YD, Fisch S, Unno K, Sereti KI \& Liao R MicroRNA-34a plays a key role in cardiac repair and regeneration following myocardial infarction. Circulation Research 2015117 450-459. (https://doi.org/10.1161/ CIRCRESAHA.117.305962)

43 Fomison-Nurse I, Saw EEL, Gandhi S, Munasinghe PE, Van Hout I, Williams MJA, Galvin I, Bunton R, Davis P, Cameron V, et al. Diabetes induces the activation of pro-ageing miR-34a in the heart, but has differential effects on cardiomyocytes and cardiac progenito cells. Cell Death and Differentiation 201825 1336-1349. (https://doi. org/10.1038/s41418-017-0047-6)

44 de Lencastre A, Pincus Z, Zhou K, Kato M, Lee SS \& Slack FJ MicroRNAs both promote and antagonize longevity in C. elegans Current Biology 201020 2159-2168. (https://doi.org/10.1016/j. cub.2010.11.015)

45 Liu N, Landreh M, Cao K, Abe M, Hendriks GJ, Kennerdell JR, Zhu Y, Wang LS \& Bonini NM The microRNA miR-34 modulates ageing and neurodegeneration in Drosophila. Nature 2012482 519-523. (https://doi.org/10.1038/nature10810)

46 Iorio MV, Visone R, Di Leva G, Donati V, Petrocca F, Casalini P, Taccioli C, Volinia S, Liu CG, Alder H, et al. MicroRNA signatures in human ovarian cancer. Cancer Research 200767 8699-8707. (https:// doi.org/10.1158/0008-5472.CAN-07-1936)

47 Ferraro A, Kontos CK, Boni T, Bantounas I, Siakouli D, Kosmidou V, Vlassi M, Spyridakis Y, Tsipras I, Zografos G, et al. Epigenetic regulation of miR-21 in colorectal cancer: ITGB4 as a novel miR-21 target and a three-gene network (miR-21-ITGBeta4-PDCD4) as predictor of metastatic tumor potential. Epigenetics 20149 129-141. (https://doi.org/10.4161/epi.26842)

48 Zhang X, Azhar G \& Wei JY The expression of microRNA and microRNA clusters in the aging heart. PLOS ONE 20127 e34688. (https://doi.org/10.1371/journal.pone.0034688)

49 Villar AV, Garcia R, Merino D, Llano M, Cobo M, Montalvo C, Martin-Duran R, Hurle MA \& Nistal JF Myocardial and circulating levels of microRNA-21 reflect left ventricular fibrosis in aortic stenosis patients. International Journal of Cardiology $2013 \mathbf{1 6 7}$ 2875-2881. (https://doi.org/10.1016/j.ijcard.2012.07.021)

50 Thum T, Gross C, Fiedler J, Fischer T, Kissler S, Bussen M, Galuppo P, Just S, Rottbauer W, Frantz S, et al. MicroRNA-21 contributes to myocardial disease by stimulating MAP kinase signalling in fibroblasts. Nature $2008 \mathbf{4 5 6}$ 980-984. (https://doi.org/10.1038/ nature07511)

51 Bei Y, Wu X, Cretoiu D, Shi J, Zhou Q, Lin S, Wang H, Cheng Y, Zhang $\mathrm{H}$, Xiao J, et al. miR-21 suppression prevents cardiac alterations induced by d-galactose and doxorubicin. Journal of Molecular and Cellular Cardiology 2018115 130-141. (https://doi org/10.1016/j.yjmcc.2018.01.007)

52 Sabatel C, Malvaux L, Bovy N, Deroanne C, Lambert V, Gonzalez ML, Colige A, Rakic JM, Noel A, Martial JA, et al. MicroRNA-21 exhibits antiangiogenic function by targeting RhoB expression in endothelial cells. PLOS ONE 20116 e16979. (https://doi.org/10.1371/journal. pone.0016979)

53 Fabbri M, Garzon R, Cimmino A, Liu Z, Zanesi N, Callegari E, Liu S, Alder H, Costinean S, Fernandez-Cymering C, et al. MicroRNA-29 family reverts aberrant methylation in lung cancer by targeting DNA methyltransferases 3A and 3B. PNAS 2007 104 15805-15810. (https://doi.org/10.1073/pnas.0707628104)

54 Garzon R, Liu S, Fabbri M, Liu Z, Heaphy CE, Callegari E, Schwind S, Pang J, Yu J, Muthusamy N, et al. MicroRNA-29b induces global DNA hypomethylation and tumor suppressor gene reexpression in acute myeloid leukemia by targeting directly DNMT3A and 3B and indirectly DNMT1. Blood 2009113 6411-6418. (https://doi. org/10.1182/blood-2008-07-170589)

55 van Rooij E, Sutherland LB, Thatcher JE, DiMaio JM, Naseem RH, Marshall WS, Hill JA \& Olson EN Dysregulation of microRNAs after myocardial infarction reveals a role of miR-29 in cardiac fibrosis. PNAS 2008105 13027-13032. (https://doi.org/10.1073/ pnas.0805038105)

56 Zhang Y, Huang XR, Wei LH, Chung AC, Yu CM \& Lan HY miR-29b as a therapeutic agent for angiotensin II-induced cardiac fibrosis by targeting TGF-beta/Smad3 signaling. Molecular Therapy 201422 974-985. (https://doi.org/10.1038/mt.2014.25)

57 Roncarati R, Viviani Anselmi C, Losi MA, Papa L, Cavarretta E, Da Costa Martins P, Contaldi C, Saccani Jotti G, Franzone A, Galastri L, et al. Circulating miR-29a, among other up-regulated microRNAs, is the only biomarker for both hypertrophy and fibrosis in patients with hypertrophic cardiomyopathy. Journal of the American College of Cardiology 201463 920-927. (https://doi.org/10.1016/j. jacc.2013.09.041)

58 Widlansky ME, Jensen DM, Wang J, Liu Y, Geurts AM, Kriegel AJ, Liu P, Ying R, Zhang G, Casati M, et al. miR-29 contributes to normal endothelial function and can restore it in cardiometabolic disorders. EMBO Molecular Medicine 201810 e8046. (https://doi.org/10.15252/ emmm.201708046)

59 Ugalde AP, Ramsay AJ, de la Rosa J, Varela I, Marino G, Cadinanos J, Lu J, Freije JM \& Lopez-Otin C Aging and chronic DNA damage response activate a regulatory pathway involving miR-29 and p53. EMBO Journal 201130 2219-2232. (https://doi.org/10.1038/ emboj.2011.124)

60 Varambally S, Cao Q, Mani RS, Shankar S, Wang X, Ateeq B, Laxman B, Cao X, Jing X, Ramnarayanan K, et al. Genomic loss of microRNA-101 leads to overexpression of histone methyltransferase 
EZH2 in cancer. Science 2008322 1695-1699. (https://doi. org/10.1126/science.1165395)

61 Chiang CW, Huang Y, Leong KW, Chen LC, Chen HC, Chen SJ \& Chou CK PKCalpha mediated induction of miR-101 in human hepatoma HepG2 cells. Journal of Biomedical Science 20101735. (https://doi.org/10.1186/1423-0127-17-35)

$62 \mathrm{Li} \mathrm{N}$, Bates DJ, An J, Terry DA \& Wang E Up-regulation of key microRNAs, and inverse down-regulation of their predicted oxidative phosphorylation target genes, during aging in mouse brain. Neurobiology of Aging 201132 944-955. (https://doi.org/10.1016/j. neurobiolaging.2009.04.020)

63 Pan Z, Sun X, Shan H, Wang N, Wang J, Ren J, Feng S, Xie L, Lu C, Yuan Y, et al. MicroRNA-101 inhibited postinfarct cardiac fibrosis and improved left ventricular compliance via the FBJ osteosarcoma oncogene/transforming growth factor-beta1 pathway. Circulation 2012126 840-850. (https://doi.org/10.1161/ CIRCULATIONAHA.112.094524)

64 Wei L, Yuan M, Zhou R, Bai Q, Zhang W, Zhang M, Huang Y \& Shi L MicroRNA-101 inhibits rat cardiac hypertrophy by targeting Rab1a. Journal of Cardiovascular Pharmacology 201565 357-363. (https://doi. org/10.1097/FJC.0000000000000203

65 Deng G, Teng Y, Huang F, Nie W, Zhu L, Huang W \& Xu H MicroRNA-101 inhibits the migration and invasion of intrahepatic cholangiocarcinoma cells via direct suppression of vascular endothelial growth factor-C. Molecular Medicine Reports 201512 7079-7085. (https://doi.org/10.3892/mmr.2015.4239)

66 Rinn JL \& Chang HY Genome regulation by long noncoding RNAs. Annual Review of Biochemistry 201281 145-166. (https://doi. org/10.1146/annurev-biochem-051410-092902)

$67 \mathrm{Wu}$ H, Yang L \& Chen LL The diversity of long noncoding RNAs and their generation. Trends in Genetics 201733 540-552. (https://doi. org/10.1016/j.tig.2017.05.004)

68 Qu S, Yang X, Li X, Wang J, Gao Y, Shang R, Sun W, Dou K \& Li H Circular RNA: a new star of noncoding RNAs. Cancer Letters 2015365 141-148. (https://doi.org/10.1016/j.canlet.2015.06.003)

69 Pamudurti NR, Bartok O, Jens M, Ashwal-Fluss R, Stottmeister C, Ruhe L, Hanan M, Wyler E, Perez-Hernandez D, Ramberger E, et al. Translation of CircRNAs. Molecular Cell 201766 9-21.e7. (https://doi. org/10.1016/j.molcel.2017.02.021)

70 Vicens Q \& Westhof E Biogenesis of circular RNAs. Cell 2014159 13-14. (https://doi.org/10.1016/j.cell.2014.09.005)

71 Legnini I, Di Timoteo G, Rossi F, Morlando M, Briganti F, Sthandier O, Fatica A, Santini T, Andronache A, Wade M, et al. Circ-ZNF609 is a circular RNA that can be translated and functions in myogenesis. Molecular Cell 201766 22-37.e9. (https://doi. org/10.1016/j.molcel.2017.02.017)

72 Zhuo M, Yuan C, Han T, Cui J, Jiao F \& Wang L A novel feedback loop between high MALAT-1 and low miR-200c-3p promotes cell migration and invasion in pancreatic ductal adenocarcinoma and is predictive of poor prognosis. BMC Cancer 201818 1032. (https://doi. org/10.1186/s12885-018-4954-9)

73 Li Q, Zhang C, Chen R, Xiong H, Qiu F, Liu S, Zhang M, Wang F, Wang Y, Zhou X, et al. Disrupting MALAT1/miR-200c sponge decreases invasion and migration in endometrioid endometrial carcinoma. Cancer Letters 2016383 28-40. (https://doi.org/10.1016/j. canlet.2016.09.019)

74 Xiao H, Tang K, Liu P, Chen K, Hu J, Zeng J, Xiao W, Yu G, Yao W, Zhou H, et al. LncRNA MALAT1 functions as a competing endogenous RNA to regulate ZEB2 expression by sponging miR-200s in clear cell kidney carcinoma. Oncotarget $2015638005-38015$. (https://doi.org/10.18632/oncotarget.5357)

75 Vausort M, Wagner DR \& Devaux Y Long noncoding RNAs in patients with acute myocardial infarction. Circulation Research 2014 115 668-677. (https://doi.org/10.1161/CIRCRESAHA.115.303836)

76 Zhu P, Yang M, Ren H, Shen G, Chen J, Zhang J, Liu J \& Sun C Long noncoding RNA MALAT1 downregulates cardiac transient outward potassium current by regulating miR-200c/HMGB1 pathway. Journal of Cellular Biochemistry 2018119 10239-10249. (https://doi. org/10.1002/jcb.27366)

77 Limana F, Germani A, Zacheo A, Kajstura J, Di Carlo A, Borsellino G, Leoni O, Palumbo R, Battistini L, Rastaldo R, et al. Exogenous high-mobility group box 1 protein induces myocardial regeneration after infarction via enhanced cardiac C-kit+ cell proliferation and differentiation. Circulation Research 200597 e73-e83. (https://doi. org/10.1161/01.RES.0000186276.06104.04)

78 Limana F, Esposito G, D'Arcangelo D, Di Carlo A, Romani S, Melillo G, Mangoni A, Bertolami C, Pompilio G, Germani A, et al. HMGB1 attenuates cardiac remodelling in the failing heart via enhanced cardiac regeneration and miR-206-mediated inhibition of TIMP-3. PLoS ONE 20116 e19845. (https://doi.org/10.1371/journal.pone.0019845)

79 Sun R \& Zhang L Long non-coding RNA MALAT1 regulates cardiomyocytes apoptosis after hypoxia/reperfusion injury via modulating miR-200a-3p/PDCD4 axis. Biomedicine and Pharmacotherapy 2019111 1036-1045. (https://doi.org/10.1016/j. biopha.2018.12.122)

80 Ye J, Tan L, Fu Y, Xu H, Wen L, Deng Y \& Liu K LncRNA SNHG15 promotes hepatocellular carcinoma progression by sponging miR141-3p. Journal of Cellular Biochemistry $201912019775-19783$. (https://doi.org/10.1002/jcb.29283)

81 Sun X, Bai Y, Yang C, Hu S, Hou Z \& Wang G Long noncoding RNA SNHG15 enhances the development of colorectal carcinoma via functioning as a ceRNA through miR-141/SIRT1/Wnt/betacatenin axis. Artificial Cells, Nanomedicine, and Biotechnology 201947 2536-2544. (https://doi.org/10.1080/21691401.2019.1621328)

82 Li Z, Yan M, Yu Y, Wang Y, Lei G, Pan Y, Li N, Gobin R \& Yu J LncRNA H19 promotes the committed differentiation of stem cells from apical papilla via miR-141/SPAG9 pathway. Cell Death and Disease 201910 130. (https://doi.org/10.1038/s41419-019-1337-3)

83 Zhou B \& Yu JW A novel identified circular RNA, circRNA_010567, promotes myocardial fibrosis via suppressing miR-141 by targeting TGF-beta1. Biochemical and Biophysical Research Communications 2017 487 769-775. (https://doi.org/10.1016/j.bbrc.2017.04.044)

84 Wu H, Zhao ZA, Liu J, Hao K, Yu Y, Han X, Li J, Wang Y, Lei W, Dong $\mathrm{N}$, et al. Long noncoding RNA Meg3 regulates cardiomyocyte apoptosis in myocardial infarction. Gene Therapy 201825 511-523. (https://doi.org/10.1038/s41434-018-0045-4)

85 Zhang J, Liang Y, Huang X, Guo X, Liu Y, Zhong J \& Yuan J STAT3induced upregulation of lncRNA MEG3 regulates the growth of cardiac hypertrophy through miR-361-5p/HDAC9 axis. Scientific Reports 20199 460. (https://doi.org/10.1038/s41598-018-36369-1)

86 Boon RA, Hofmann P, Michalik KM, Lozano-Vidal N, Berghauser D, Fischer A, Knau A, Jae N, Schurmann C \& Dimmeler S Long noncoding RNA Meg3 controls endothelial cell aging and function: implications for regenerative angiogenesis. Journal of the American College of Cardiology 201668 2589-2591. (https://doi.org/10.1016/j. jacc.2016.09.949)

87 Piccoli MT, Gupta SK, Viereck J, Foinquinos A, Samolovac S, Kramer FL, Garg A, Remke J, Zimmer K, Batkai S, et al. Inhibition of the cardiac fibroblast-enriched lncRNA Meg3 prevents cardiac fibrosis and diastolic dysfunction. Circulation Research 2017121 575-583. (https://doi.org/10.1161/CIRCRESAHA.117.310624)

88 Tong P, Peng QH, Gu LM, Xie WW \& Li WJ LncRNA-MEG3 alleviates high glucose induced inflammation and apoptosis of retina epithelial cells via regulating miR-34a/SIRT1 axis. Experimental and Molecular Pathology 2019107 102-109. (https://doi.org/10.1016/j. yexmp.2018.12.003)

89 Huang XL, Gao Y, Qin JJ \& Lu S The mechanism of long non-coding RNA MEG3 for hepatic ischemia-reperfusion: mediated by miR-34a/ Nrf2 signaling pathway. Journal of Cellular Biochemistry 2018119 1163-1172. (https://doi.org/10.1002/jcb.26286)

90 Wang H, Jin Z, Pei T, Song W, Gong Y, Chen D, Zhang L, Zhang M \& Zhang G Long noncoding RNAs C2dat1 enhances vascular smooth 
muscle cell proliferation and migration by targeting MiR-34a-5p. Journal of Cellular Biochemistry 2019120 3001-3008. (https://doi. org/10.1002/jcb.27070)

91 Wang HR, Jin ZL, Pei T, Song WH, Gong Y, Chen DL, Zhang L, Zhang MC \& Zhang GC Long noncoding RNAs C2dat1 enhances vascular smooth muscle cell proliferation and migration by targeting MiR-34a-5p. Journal of Cellular Biochemistry 2019120 3001-3008. (https://doi.org/10.1002/jcb.27070)

92 Jiang Y, Mo H, Luo J, Zhao S, Liang S, Zhang M \& Yuan J HOTAIR is a potential novel biomarker in patients with congenital heart diseases. BioMed Research International 20182018 2850657. (https://doi. org/10.1155/2018/2850657)

93 Greco S, Zaccagnini G, Perfetti A, Fuschi P, Valaperta R, Voellenkle C, Castelvecchio S, Gaetano C, Finato N, Beltrami AP, et al. Long noncoding RNA dysregulation in ischemic heart failure. Journal of Translational Medicine 201614 183. (https://doi.org/10.1186/s12967016-0926-5)

94 Gao L, Wang X, Guo S, Xiao L, Liang C, Wang Z, Li Y, Liu Y, Yao R, Liu Y, et al. LncRNA HOTAIR functions as a competing endogenous RNA to upregulate SIRT1 by sponging miR-34a in diabetic cardiomyopathy. Journal of Cellular Physiology 2019234 4944-4958. (https://doi.org/10.1002/jcp.27296)

95 Li A, Peng R, Sun Y, Liu H, Peng H \& Zhang Z LincRNA 1700020I14Rik alleviates cell proliferation and fibrosis in diabetic nephropathy via miR-34a-5p/Sirt1/HIF-1alpha signaling. Cell Death and Disease 20189 461. (https://doi.org/10.1038/s41419-018-0527-8)

96 Yang LS, Wang B, Zhou QQ, Wang YR, Liu XG, Liu ZM \& Zhan ZZ MicroRNA-21 prevents excessive inflammation and cardiac dysfunction after myocardial infarction through targeting KBTBD7. Cell Death and Disease 20189 769. (https://doi.org/10.1038/s41419018-0805-5)

97 Zhu B, Gong Y, Yan G, Wang D, Qiao Y, Wang Q, Liu B, Hou J, Li R \& Tang C Down-regulation of lncRNA MEG3 promotes hypoxiainduced human pulmonary artery smooth muscle cell proliferation and migration via repressing PTEN by sponging miR-21. Biochemical and Biophysical Research Communications 2018495 2125-2132. (https://doi.org/10.1016/j.bbrc.2017.11.185)

98 Hao L, Wang J \& Liu N Long noncoding RNA TALNEC2 regulates myocardial ischemic injury in $\mathrm{H} 9 \mathrm{c} 2$ cells by regulating miR-21/ PDCD4-medited activation of Wnt/beta-catenin pathway. Journal of Cellular Biochemistry 2019120 12912-12923. (https://doi. org/10.1002/jcb.28562)

99 Li FP, Lin DQ \& Gao LY LncRNA TUG1 promotes proliferation of vascular smooth muscle cell and atherosclerosis through regulating miRNA-21/PTEN axis. European Review for Medical and Pharmacological Sciences 201822 7439-7447. (https://doi.org/10.26355/ eurrev_201811_16284)

100 Uchida S \& Dimmeler S Long noncoding RNAs in cardiovascular diseases. Circulation Research 2015116 737-750. (https://doi. org/10.1161/CIRCRESAHA.116.302521)

101 Chen C, Cheng GQ, Yang XN, Li CS, Shi R \& Zhao NN Tanshinol suppresses endothelial cells apoptosis in mice with atherosclerosis via lncRNA TUG1 up-regulating the expression of miR-26a. American Journal of Translational Research 20168 2981-2991.

102 Wu ZH, He YY, Li DL, Fang X, Shang T, Zhang HK \& Zheng XT Long noncoding RNA MEG3 suppressed endothelial cell proliferation and migration through regulating miR-21. American Journal of Translational Research 20179 3326-3335.

103 Halimulati M, Duman B, Nijiati J \& Aizezi A Long noncoding RNA TCONS_00024652 regulates vascular endothelial cell proliferation and angiogenesis via microRNA-21. Experimental and Therapeutic Medicine 201816 3309-3316. (https://doi.org/10.3892/ etm.2018.6594)

104 Liu YH, He AB, Liu BE, Huang ZX \& Mei HB Potential role of IncRNA H19 as a cancer biomarker in human cancers detection and diagnosis: a pooled analysis based on 1585 subjects.
BioMed Research International 20192019 9056458. (https://doi. org/10.1155/2019/9056458)

105 Lv MX, Zhong ZY, Huang MG, Tian Q, Jiang R \& Chen JX lncRNA $\mathrm{H} 19$ regulates epithelial-mesenchymal transition and metastasis of bladder cancer by miR-29b-3p as competing endogenous RNA. Biochimica et Biophysica Acta: Molecular Cell Research 20171864 1887-1899. (https://doi.org/10.1016/j.bbamcr.2017.08.001)

106 Huang YJ, Wang LP, Mao Y \& Nan GX Long noncoding RNA-H19 contributes to atherosclerosis and induces ischemic stroke via the upregulation of acid phosphatase 5. Frontiers in Neurology 20191032. (https://doi.org/10.3389/fneur.2019.00032)

107 Chen YG, Janckila A, Chao TY, Yeh RH, Gao HW, Lee SH, Yu JC, Liao GS \& Dai MS Association of tartrate-resistant acid phosphatase-expressed macrophages and metastatic breast cancer progression. Medicine 201594 e2165. (https://doi.org/10.1097/ MD.0000000000002165)

108 Xiao LL, Gu YL, Sun YL, Chen J, Wang XF, Zhang YZ, Gao L \& Li L The long noncoding RNA XIST regulates cardiac hypertrophy by targeting miR-101. Journal of Cellular Physiology 2019234 13680-13692. (https://doi.org/10.1002/jcp.28047)

109 Chen DL, Ju HQ, Lu YX, Chen LZ, Zeng ZL, Zhang DS, Luo HY, Wang F, Qiu MZ, Wang DS, et al. Long non-coding RNA XIST regulates gastric cancer progression by acting as a molecular sponge of miR-101 to modulate EZH2 expression. Journal of Experimental and Clinical Cancer Research 201635 142. (https://doi.org/10.1186/ s13046-016-0420-1)

110 Wu XL, Dinglin XX, Wang X, Luo W, Shen Q, Li Y, Gu L, Zhou QH, Zhu HT, Li YJ, et al. Long noncoding RNA XIST promotes malignancies of esophageal squamous cell carcinoma via regulation of miR-101/EZH2. Oncotarget 20178 76015-76028. (https://doi. org/10.18632/oncotarget.18638)

111 Vaiserman A \& Lushchak O Implementation of longevitypromoting supplements and medications in public health practice: achievements, challenges and future perspectives. Journal of Translational Medicine 201715 160. (https://doi.org/10.1186/s12967017-1259-8)

112 Izzo C, Carrizzo A, Alfano A, Virtuoso N, Capunzo M, Calabrese M, De Simone E, Sciarretta S, Frati G, Oliveti M, et al. The impact of aging on cardio and cerebrovascular diseases. International Journal of Molecular Sciences 2018 19. (https://doi.org/10.3390/ijms19020481)

113 Sebastiani P, Bae H, Sun FX, Andersen SL, Daw EW, Malovini A, Kojima T, Hirose N, Schupf N, Puca A, et al. Meta-analysis of genetic variants associated with human exceptional longevity. Aging 20135 653-661. (https://doi.org/10.18632/aging.100594)

114 Giuliani C, Garagnani P \& Franceschi C Genetics of human longevity within an eco-evolutionary nature-nurture framework. Circulation Research 2018123 745-772. (https://doi.org/10.1161/ CIRCRESAHA.118.312562)

115 Deelen J, Beekman M, Uh HW, Broer L, Ayers KL, Tan Q, Kamatani Y, Bennet AM, Tamm R, Trompet S, et al. Genome-wide association meta-analysis of human longevity identifies a novel locus conferring survival beyond 90 years of age. Human Molecular Genetics 201423 4420-4432. (https://doi.org/10.1093/hmg/ddu139)

116 Schachter F, Faure-Delanef L, Guenot F, Rouger H, Froguel P, LesueurGinot L \& Cohen D Genetic associations with human longevity at the APOE and ACE loci. Nature Genetics 19946 29-32. (https://doi org/10.1038/ng0194-29)

117 Willcox BJ, Donlon TA, He Q, Chen R, Grove JS, Yano K, Masaki KH, Willcox DC, Rodriguez B \& Curb JD FOXO3A genotype is strongly associated with human longevity. PNAS 2008105 13987-13992. (https://doi.org/10.1073/pnas.0801030105)

118 Christensen K, Johnson TE \& Vaupel JW The quest for genetic determinants of human longevity: challenges and insights. Nature Reviews: Genetics 20067 436-448. (https://doi.org/10.1038/nrg1871)

119 Budovsky A, Craig T, Wang J, Tacutu R, Csordas A, Lourenco J, Fraifeld VE \& de Magalhaes JP LongevityMap: a database of human

This work is licensed under a Creative Commons Attribution-NonCommercial 4.0 International License. dicom Bioscientifica com at 04/26/2023 06:33:57 AM 
genetic variants associated with longevity. Trends in Genetics 201329 559-560. (https://doi.org/10.1016/j.tig.2013.08.003)

120 Deelen J, Beekman M, Uh HW, Helmer Q, Kuningas M, Christiansen L, Kremer D, van der Breggen R, Suchiman HE, Lakenberg $\mathrm{N}$, et al. Genome-wide association study identifies a single major locus contributing to survival into old age; the APOE locus revisited. Aging Cell 201110 686-698. (https://doi.org/10.1111/ j.1474-9726.2011.00705.x)

121 Nebel A, Kleindorp R, Caliebe A, Nothnagel M, Blanche H, Junge O, Wittig M, Ellinghaus D, Flachsbart F, Wichmann HE, et al. A genome-wide association study confirms APOE as the major gene influencing survival in long-lived individuals. Mechanisms of Ageing and Development 2011132 324-330. (https://doi.org/10.1016/j. mad.2011.06.008)

122 Fortney K, Dobriban E, Garagnani P, Pirazzini C, Monti D, Mari D, Atzmon G, Barzilai N, Franceschi C, Owen AB, et al. Genome-wide scan informed by age-related disease identifies loci for exceptional human longevity. PLoS Genetics 201511 e1005728. (https://doi. org/10.1371/journal.pgen.1005728)

123 Sebastiani P, Gurinovich A, Nygaard M, Sasaki T, Sweigart B, Bae H, Andersen SL, Villa F, Atzmon G, Christensen K, et al. APOE alleles and extreme human longevity. Journals of Gerontology 2019 74 44-51. (https://doi.org/10.1093/gerona/gly174)

124 Safieh M, Korczyn AD \& Michaelson DM ApoE4: an emerging therapeutic target for Alzheimer's disease. BMC Medicine 20191764. (https://doi.org/10.1186/s12916-019-1299-4)

125 Villa F, Carrizzo A, Spinelli CC, Ferrario A, Malovini A, Maciag A, Damato A, Auricchio A, Spinetti G, Sangalli E, et al. Genetic analysis reveals a longevity-associated protein modulating endothelial function and angiogenesis. Circulation Research 2015117 333-345. (https://doi.org/10.1161/CIRCRESAHA.117.305875)

126 Villa F, Malovini A, Carrizzo A, Spinelli CC, Ferrario A, Maciag A, Madonna M, Bellazzi R, Milanesi L, Vecchione C, et al. Serum BPIFB4 levels classify health status in long-living individuals. Immunity and Ageing 201512 27. (https://doi.org/10.1186/s12979015-0054-8)

127 Spinetti G, Sangalli E, Specchia C, Villa F, Spinelli C, Pipolo R, Carrizzo A, Greco S, Voellenkle C, Vecchione C, et al. The expression of the BPIFB4 and CXCR4 associates with sustained health in longliving individuals from Cilento-Italy. Aging 20179 370-380. (https:// doi.org/10.18632/aging.101159)

128 Vecchione C, Villa F, Carrizzo A, Spinelli CC, Damato A, Ambrosio M, Ferrario A, Madonna M, Uccellatore A, Lupini S, et al. A rare genetic variant of BPIFB4 predisposes to high blood pressure via impairment of nitric oxide signaling. Scientific Reports 20177 9706. (https://doi. org/10.1038/s41598-017-10341-x)

129 Puca AA, Carrizzo A, Spinelli C, Damato A, Ambrosio M, Villa F, Ferrario A, Maciag A, Fornai F, Lenzi P, et al. Single systemic transfer of a human gene associated with exceptional longevity halts the progression of atherosclerosis and inflammation in ApoE knockout mice through a CXCR4-mediated mechanism. European Heart Journal 2019 ehz459. (https://doi.org/10.1093/eurheartj/ehz459)

130 Ciaglia E, Montella F, Maciag A, Scala P, Ferrario A, Banco C, Carrizzo A, Spinelli CC, Cattaneo M, De Candia P, et al. Longevityassociated variant of BPIFB4 mitigates monocyte-mediated acquired immune response. Journals of Gerontology: Series A 201974 (Supplement_1) S38-S44. (https://doi.org/10.1093/gerona/glz036)

131 Spinelli CC, Carrizzo A, Ferrario A, Villa F, Damato A, Ambrosio M, Madonna M, Frati G, Fucile S, Sciaccaluga M, et al. LAV-BPIFB4 isoform modulates eNOS signalling through Ca2+/PKC-alphadependent mechanism. Cardiovascular Research 2017113 795-804. (https://doi.org/10.1093/cvr/cvx072)

132 Pacheco LM, Gomez LA, Dias J, Ziebarth NM, Howard GA \& Schiller PC Progerin expression disrupts critical adult stem cell functions involved in tissue repair. Aging 20146 1049-1063. (https:// doi.org/10.18632/aging.100709)

133 Hamczyk MR \& Andres V Vascular smooth muscle cell loss underpins the accelerated atherosclerosis in Hutchinson-Gilford progeria syndrome. Nucleus 201910 28-34. (https://doi.org/10.1080/1949103 4.2019.1589359)

134 Harhouri K, Frankel D, Bartoli C, Roll P, De Sandre-Giovannoli A \& Levy N An overview of treatment strategies for Hutchinson-Gilford progeria syndrome. Nucleus 20189 246-257. (https://doi.org/10.1080 /19491034.2018.1460045)

135 Scaffidi P \& Misteli T Lamin A-dependent misregulation of adult stem cells associated with accelerated ageing. Nature Cell Biology 2008 10 452-459. (https://doi.org/10.1038/ncb1708)

136 Zhavoronkov A, Smit-McBride Z, Guinan KJ, Litovchenko M \& Moskalev A Potential therapeutic approaches for modulating expression and accumulation of defective lamin A in laminopathies and age-related diseases. Journal of Molecular Medicine 201290 1361-1389. (https://doi.org/10.1007/s00109-012-0962-4)

137 Al Haj Zen A \& Madeddu P Notch signalling in ischaemia-induced angiogenesis. Biochemical Society Transactions 200937 1221-1227. (https://doi.org/10.1042/BST0371221)

138 Kreienkamp R, Croke M, Neumann MA, Bedia-Diaz G, Graziano S, Dusso A, Dorsett D, Carlberg C \& Gonzalo S Vitamin D receptor signaling improves Hutchinson-Gilford progeria syndrome cellular phenotypes. Oncotarget 20167 30018-30031. (https://doi. org/10.18632/oncotarget.9065)

139 Ashapkin VV, Kutueva LI, Kurchashova SY \& Kireev II Are there common mechanisms between the Hutchinson-Gilford progeria syndrome and natural aging? Frontiers in Genetics 201910455. (https://doi.org/10.3389/fgene.2019.00455)

140 Scaffidi P \& Misteli T Lamin A-dependent nuclear defects in human aging. Science 2006312 1059-1063. (https://doi.org/10.1126/ science.1127168)

141 Scaffidi P \& Misteli T Reversal of the cellular phenotype in the premature aging disease Hutchinson-Gilford progeria syndrome. Nature Medicine 200511 440-445. (https://doi.org/10.1038/nm1204)

Received in final form 12 December 2019

Accepted 16 January 2020

Accepted Manuscript published online 16 January 2020 https://vb.bioscientifica.com

https://doi.org/10.1530/VB-19-0029 (c) 2020 The authors Published by Bioscientifica Ltd

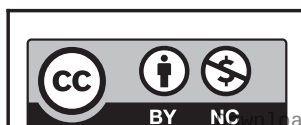

This work is licensed under a Creative Commons Attribution-NonCommercial 4 . O International License. aled from Bioscientifica com at 04/26/2023 06:33:57AM 